\title{
Mothers' satisfaction with referral hospital delivery service in Amhara Region, Ethiopia
}

\author{
Azmeraw Tayelgn', Desalegn T Zegeye ${ }^{2^{*}}$ and Yigzaw Kebede ${ }^{2}$
}

\begin{abstract}
Background: A woman's satisfaction with the delivery service may have immediate and long-term effects on her health and subsequent utilization of the services. Providing satisfying delivery care increases service utilization. The objective of this study is to assess the satisfaction of mothers with referral hospitals' delivery service and identify some possible factors affecting satisfaction in Amhara region of Ethiopia.

Methods: A hospital-based cross-sectional survey that involved an exit interview was conducted from September to November 2009 in three referral hospitals in Ethiopia. A total of 417 delivering mothers were enrolled in the study. Client satisfaction was measured using a survey instrument adopted from the Donabedian quality assessment framework. We collect data systematically from every other postnatal woman who delivered in the referral hospitals. Multivariate and binary logistic regression was applied to identify the relative effect of each explanatory variable on the outcome (satisfaction).

Results: The proportion of mothers who were satisfied with delivery care in this study was $61.9 \%$. Women's satisfaction with delivery care was associated with wanted status of the pregnancy, immediate maternal condition after delivery, waiting time to see the health worker, availability of waiting area, care providers' measure taken to assure privacy during examinations, and amount of cost paid for service.
\end{abstract}

Conclusions: The overall satisfaction of hospital delivery services in this study is found to be suboptimal. The study strongly suggests that more could be done to assure that services provided are more patient centered.

\section{Background}

One of the Millennium Development Goals (MDG5) is to reduce the maternal mortality ratio by $3 / 4$ between 1990 and 2015. Pregnancy and childbirth claim the lives of an estimated half a million of women globally each year [1]. More than half of these deaths occur in Africa [1]. Ethiopia is one of the countries that have highest maternal mortality rates (MMR) in the world which is estimated to be $673 / 100,000$ live births [2]. Part of this mortality is attributed to poor delivery care [3].

The Ethiopian government and international organizations are working for making hospital delivery services accessible and usable for all pregnant women but still the proportion of births attended by a skilled birth attendant is about $18.4 \%$ [4] in 2009 which was much lower than the average level in developing countries in

\footnotetext{
* Correspondence: zdesalegn@gmail.com

${ }^{2}$ Department of Epidemiology and Biostatistics, University of Gondar, P.O.Box 196, Gondar, Ethiopia

Full list of author information is available at the end of the article
}

general (59\%), Sub-Saharan regions (44\%), and very far from MDG target of $90 \%$ coverage [1,3]. The reasons forwarded by researchers for the higher maternal mortality, and lower coverage of skilled delivery in Ethiopia include mothers' unhappy health institutional delivery experience [3,5].

In Ethiopia, dire health institutional delivery experience limits women's ability to seek care for subsequent pregnancies [3,5]. A midterm assessment of the third Ethiopian Health Sector Development Program (HSDP III) also identified poor quality skilled birth attendance as one of the critical bottlenecks for improving the lower utilization of hospital delivery [5]. Many studies have been conducted on quality of maternity care with hospital and health centers in Ethiopia [6,7]. These studies suggest that the quality of maternity care in Ethiopia is poor. This includes not only the quality of clinical care but also gender sensitivity, preservation of dignity and cultural sensitivity [5,7]. These factors together with

\section{() Biomed Central}


the community level factors explain the extremely low utilization of health services for delivery $[3,6,7]$.

Satisfaction is a meaningful output indicator of quality health care [8-10]. Various studies have reported that satisfied service users are more likely to utilize health services, comply with services and follow ups, and continue with the health care [11-14]. Satisfaction with childbirth experience is important to the woman, infant's health and well-being, and mother-infant relationship. Studies reported that a mother's positive perception of birth experience has been linked to positive feelings toward her infant and adaptation to the mothering role [15-17].

A community based study conducted in Kenya among women who delivered in health facilities showed that over half $(56 \%)$ of women are satisfied with delivery care [11].

Despite having many studies done elsewhere, there is paucity of data concerning mother's satisfaction with childbirth services in referral hospitals in Ethiopia. Hence, this study was conducted to show Ethiopian case at referral level in Amhara region of Ethiopia.

\section{Methods}

\section{Study design}

A hospital-based cross-sectional survey was conducted from September 2009 to November 2009.

\section{Study area}

This study was conducted in three public referral hospitals of Amhara region, northwest Ethiopia. These three referral hospitals were University of Gondar Teaching and Referral Hospital (UOGTRH), Felege Hiwot referral hospital (FRH), and Dessie referral hospital (DRH). Each referral hospital's catchment population is estimated to be 5-7 million people.

\section{Study population}

Selected mothers who visited the three referral hospitals for delivery service during the data collection period were the study population.

\section{Sample size}

The sample size for this study was determined using single population proportion formula considering the assumptions: Proportion of delivering mothers satisfied with hospital delivery care service as $56 \%(\mathbf{p}=0.56)$ [11]. Level of significance to be $5 \%(\alpha=0.05), \mathbf{Z} \alpha / 2=$ 1.96 and margin of error to be $5 \%(\mathbf{d}=0.05)$. Adding non responses rate of $10 \%$, a total sample size of 417 delivering mothers were included.

\section{Sampling Procedure}

The total sample size was allocated proportionally to each of the hospitals by reviewing the number of deliveries attended in the $1^{\text {st }}$ and $2^{\text {nd }}$ quarter of 2009 . Data were collected from every other postnatal woman who received delivery care in the three hospitals.

\section{Data collection instrument}

The data collection instrument was closed-ended questionnaire. Delivery service satisfaction related questions were adopted from the Donabedian quality assessment framework [8] and presented using a 5-scale likert scale (1-very dissatisfied, 2-dissatisfied, 3-neutral, 4-satisfied, and 5-very satisfied).

The first draft of the English questionnaire was translated to Amharic language by independent translators then back to English language to check for consistency. The questionnaire was pre tested on 40 postnatal mothers at the University of Gondar Teaching and Referral Hospital one month prior to the actual data collection.

\section{Data collection}

Six female nurses who were fluent in Amharic and who were not working in the study sites were recruited for data collection. Three days (two days theoretical and one day practical) training was given before the actual data collection.

\section{Data analysis}

The completed questionnaires were checked for completeness and consistency by the investigators. Data was entered, cleaned and analyzed using SPSS version 16 (SPSS Inc., Chicago). During analysis, the responses of 'very satisfied' and 'satisfied' were classified as satisfied and responses of 'very dissatisfied', 'dissatisfied' and 'neutral' as unsatisfied. Neutral responses were classified as dissatisfied considering that they may represent a fearful way of expressing dissatisfaction. This is likely because the interview was undertaken within the hospitals and mothers may have been reluctant to express their dissatisfaction feeling of the services they received.

For the overall satisfaction level, those who were satisfied in greater or equal to $75 \%$ of the items were categorized under "satisfied" and those who were satisfied in less than $75 \%$ of the items were categorized as "un satisfied". Descriptive statistics was computed for the study variables. Frequency distribution tables were used to describe most of the findings and graphs were also plotted for some. To determine factors associated with mother's satisfaction bivariate binary logistic regression and multivariate stepwise logistic regression were applied. Adjusted odds ratio was used to determine the strength of association between selected variables.

\section{Ethical considerations}

The study proposal was approved by Institutional Review Board of the College of Medicine and Health 
Sciences of the University of Gondar. Informed oral consent was obtained from each study participant. Confidentiality was assured by making the questionnaire anonymous.

\section{Results}

\section{Socio-demographic characteristics}

A total of 417 delivering mothers from three referral hospitals participated in the exit survey with $146(35 \%)$ of the women obtained from the UOGTRH, 150(36\%) from FRH and the rest 121(29\%) from DRH.

The mean \pm SD age of the mothers was $25.9 \pm 5.2$ years. One hundred and twenty eight $(30.7 \%)$ were with no formal education. The majority $(89.2 \%)$ were married. One hundred thirty five (32.3\%) were house wives while $86(20.7 \%)$ were government employees. Two hundred ninety six (71\%) mothers came from urban areas. Three hundred and forty (81.5\%) were Amhara by ethnicity. About three fourth (302) of the delivering mothers were Orthodox Christians by religion (Table 1). The median household income of the delivering mothers was 765 ETB (47.8USD). Three hundred ninety one mothers (98.3\%) paid for the service received. The average payment by mothers was 157 ETB.

\section{Obstetrics characteristics of delivering mothers}

For $47.5 \%$ of women, this was the first delivery, $42.2 \%$ had had 2-5 deliveries; and $10.3 \%$ of women had had 5 or more deliveries. Nearly a quarter of women had had an unwanted birth. About $64.5 \%$ of the mothers' do not have previous health facility delivery experience. The majority (84.2\%) had one or more ANC visits and 15.8\% did not attend ANC. Over a fifth of women (21\%) had a self-reported complication in pregnancy. Normal vaginal delivery was the commonest mode of delivery $(53.7 \%)$ followed by assisted delivery (24.5\%) and caesarean section (21.8\%) (Table 2).

\section{Mothers' satisfaction on delivery care}

The proportion of mothers who were satisfied with delivery care in this study was $61.9 \%$. Dissatisfaction was highest (74.7\%) among women delivering at UOGTRH.

Of all satisfaction levels, client privacy related satisfaction $(46.7 \%)$, health facility distance related satisfaction (51.4\%), and amount of cost paid related satisfaction (52.7\%) were the first three least values (Figure 1).

Results of multivariate stepwise logistic regression indicated that health facility related factors and health providers' characteristics were important predicators of the overall maternal satisfaction.

Women's satisfaction with delivery care was associated with wanted status of the pregnancy [AOR $=2.2,95 \%$ CI:1.2,3.93)], favourable immediate maternal condition after delivery $[\mathrm{AOR}=2.1,95 \% \mathrm{CI}: 1.12,3.93)$ ], short
Table 1 Socio Demographic Characteristics of delivering mothers in referral hospitals of Amhara Region, Ethiopia, September - November $2009(n=417)$

\begin{tabular}{|c|c|}
\hline Characteristics & $\begin{array}{l}\text { Total }(n=417) \\
N(\%)\end{array}$ \\
\hline \multicolumn{2}{|l|}{ Age (in years) } \\
\hline$<20$ years & $37(8.9)$ \\
\hline 20-34 years & $350(83.9)$ \\
\hline $35-49$ years & $30(7.2)$ \\
\hline \multicolumn{2}{|l|}{ Marital status } \\
\hline Married & $372(89.2)$ \\
\hline Single & $39(9.4)$ \\
\hline Divorced & $6(1.4)$ \\
\hline \multicolumn{2}{|l|}{ Ethnicity } \\
\hline Amhara & $340(81.5)$ \\
\hline Tigray & $36(8.7)$ \\
\hline Oromo & $9(4.5)$ \\
\hline Agew & $6(1.4)$ \\
\hline Others & $16(3.9)$ \\
\hline \multicolumn{2}{|l|}{ Religion } \\
\hline Orthodox & $302(72.5)$ \\
\hline Muslim & 107(25.6) \\
\hline Protestant & $8(1.9)$ \\
\hline \multicolumn{2}{|l|}{ Educational Status } \\
\hline No formal education & $128(30.7)$ \\
\hline Grade1-6 & $69(16.5)$ \\
\hline Grade7-12 & 158(37.9) \\
\hline Above-12 & $62(14.9)$ \\
\hline \multicolumn{2}{|l|}{ Occupation } \\
\hline House wife & $135(32.3)$ \\
\hline Government employee & $86(20.7)$ \\
\hline Farmer & 78(18.7) \\
\hline Merchant & $51(12.2)$ \\
\hline Student & $42(10.1)$ \\
\hline Others & $25(6.0)$ \\
\hline \multicolumn{2}{|l|}{ Residence } \\
\hline Urban & 296(71.0) \\
\hline Rural & $121(29.0)$ \\
\hline \multicolumn{2}{|c|}{ Hospital delivery took place } \\
\hline UOGTRH & $146(35)$ \\
\hline $\mathrm{FRH}$ & $150(36)$ \\
\hline $\mathrm{DRH}$ & $121(29)$ \\
\hline
\end{tabular}

waiting time $[\mathrm{AOR}=2.9,95 \% \mathrm{CI}: 1.14,7.58)]$, perceived availability of waiting area $[\mathrm{AOR}=6.3,95 \%$ CI:3.33,11.88)], care providers measure taken to assure privacy during examinations $[\mathrm{AOR}=2.1,95 \% \mathrm{CI}$ : $1.13,3.83)]$, and amount of cost paid for service [AOR = 1.9 95\% CI:1.15,3.60)] (Table 3 and 4).

Figure 2 displays responses to questions exploring the willingness of delivering mothers to recommend the hospital to family or friend. Overall, $69.1 \%$ of women were very likely to recommend the hospital where they 
Table 2 Obstetrics characteristics of respondents in referral hospitals of Amhara Region, Ethiopia, September-November 2009( $n=417)$

\begin{tabular}{ll}
\hline Obstetric characteristics & Total $(\mathbf{n}=\mathbf{4 1 7}) \mathbf{N}(\%)$ \\
\hline Parity (number including the new baby) & \\
One & $198(47.5)$ \\
Two to five & $176(42.2)$ \\
More than five & $43(10.3)$ \\
Reason for visit & \\
Planned delivery & $342(82.0)$ \\
Referral delivery & $75(18)$ \\
Wanted status of pregnancy & \\
Wanted & $308(73.9)$ \\
Unwanted & $109(26.1)$ \\
Mode of delivery & \\
Spontaneous vaginal delivery(SVD) & $224(53.7)$ \\
Assisted delivery & $102(24.5)$ \\
Caesarean section(C/S) & $91(21.8)$ \\
Immediate maternal condition after delivery & \\
Normal & $328(78.7)$ \\
With complications & $89(21.3)$ \\
Fetal outcome & \\
Live birth & $374(89.7)$ \\
Stillbirth & $43(10.3)$ \\
ANC follow up & \\
Yes & $351(84.2)$ \\
No & $66(15.8)$ \\
\hline
\end{tabular}

delivered to others. Only $57.5 \%$ of women who deliver at University of Gondar Teaching and Referral Hospital were willing to recommend the hospital to a family or a friend. On the contrary Felege Hiwot Referral Hospital was recommended by $83.3 \%$ of the mothers who delivered there. This shows a statistically significant difference with $\mathrm{X}^{2}$ of 24.1 and $\mathrm{p}<0.001$. Thinking about their experience, only $287(68.8 \%)$ of the delivering mothers are likely to deliver in the hospital where they deliver again.

\section{Discussion}

This paper presents a study that estimated the level of mothers' satisfaction with referral hospitals' maternity care in Amhara Region of Ethiopia. The overall proportion of mothers who were satisfied with delivery care in this study was $61.9 \%$. This percentage is very low compared to other studies in developing countries - 92.5\% in Côte d'Ivoire [18] but it is comparable to a study in Nairobi, Kenya-56\% [11] and greater than a study in Sri Lanka 48\% [12]. This variation may be because of a real difference in quality of services provided, expectation of mothers or the type of health facilities. Studies conducted in Canada [19], Kenya [11] and Sir Lanka [12] suggest that services dealing with referred patients or complicated deliveries yield less satisfaction.

In this study delivering mothers satisfactions was predicted by wanted status of the pregnancy, immediate

\section{Examination area cleanness and comfort Waiting time to see health worker Courtsy and respect of staff Information and education service overall cleanness of the facility Completeness of information Access and cleanness of toilet Confidentiality and truest in provider Availability of drugs and supplies Waiting area cleanness and comfort Cost paid to service Health facility distance level of Privacy during delivery}

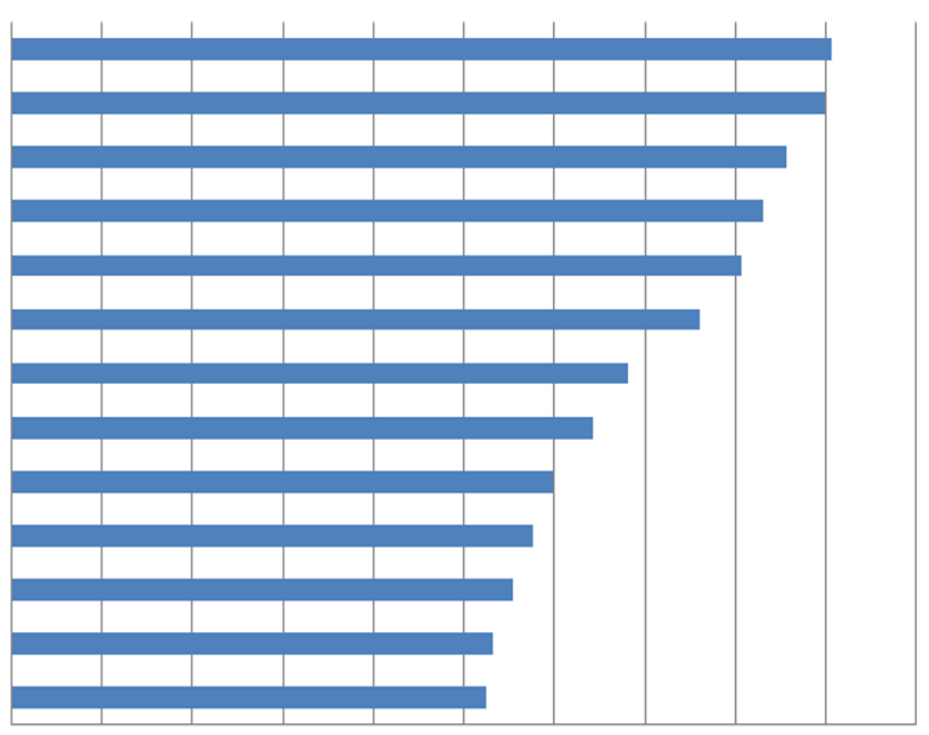

$\begin{array}{lllllllllll}0 \% & 10 \% & 20 \% & 30 \% & 40 \% & 50 \% & 60 \% & 70 \% & 80 \% & 90 \% & 100 \%\end{array}$

Figure 1 Major dimensions of care and average satisfaction scores by postnatal mothers delivered in 3 Referral hospitals in Amhara Region, Ethiopia. 
Table 3 Socio-demographic characteristics associated with mothers' satisfaction in referral hospitals of Amhara Region, Ethiopia, September-November, 2009

\begin{tabular}{|c|c|c|c|c|}
\hline & Satisfied & Unsatisfied & COR $(95 \% \mathrm{Cl})$ & AOR $(95 \% \mathrm{Cl})$ \\
\hline \multicolumn{5}{|l|}{ Age (in years) } \\
\hline$<20$ years & $20(4.8)$ & $17(4.1)$ & $1.00^{*}$ & $1.00^{*}$ \\
\hline 20-34 years & $216(51.8)$ & 134(32.1) & $1.4(0.69,2.71)$ & $0.7(0.28,1.99)$ \\
\hline $35-49$ years & $22(5.3)$ & $8(1.9)$ & $2.3(0.83,6.59)$ & $1.5(0.35,6.21)$ \\
\hline \multicolumn{5}{|l|}{ Marital Status } \\
\hline Single & $19(4.6)$ & $20(4.8)$ & $1.00^{*}$ & $1.00^{*}$ \\
\hline Married & $236(56.6)$ & 136(32.6) & $1.8(0.94,3.54)$ & $0.5(0.14,1.58)$ \\
\hline Divorced & $3(0.7)$ & $3(0.7)$ & $1.1(0.19,5.87)$ & $1.4(0.13,15.88)$ \\
\hline \multicolumn{5}{|l|}{ Religion } \\
\hline Orthodox & 173(41.6) & 129(31.0) & $1.00^{*}$ & $1.00^{*}$ \\
\hline Muslim & $79(19.0)$ & $28(6.7)$ & $2.1(1.29,3.43)^{* *}$ & $1.8(0.97,3.27)$ \\
\hline protestant & $5(1.2)$ & $2(0.5)$ & $1.9(0.36,9.76)$ & $1.1(0.13,10.28)$ \\
\hline \multicolumn{5}{|l|}{ Educational Status } \\
\hline No formal education & 79(18.9) & 49(11.8) & $1.00^{*}$ & $1.00^{*}$ \\
\hline Grade 1 - 6 & $42(10.1)$ & $27(6.5)$ & $1.0(0.53,1.76)$ & $0.9(0.39,2.32)$ \\
\hline Grade 7 - 12 & $91(21.8)$ & $67(16.1)$ & $0.8(0.52,1.36)$ & $1.6(0.66,3.95)$ \\
\hline Diploma and above & $46(11.0)$ & $16(3.8)$ & $1.8(0.91,3.49)$ & $1.8(0.49,6.72)$ \\
\hline \multicolumn{5}{|l|}{ Occupation } \\
\hline Governmental employee & $57(14.5)$ & $29(7.3)$ & $1.00^{*}$ & $1.00^{*}$ \\
\hline Merchant & $32(8.1)$ & $19(4.8)$ & $0.9(0.42,1.77)$ & $0.9(0.29,2.72)$ \\
\hline Farmer & $52(13.2)$ & $26(6.6)$ & $1.0(0.53,1.95)$ & $1.5(0.40,5.34)$ \\
\hline House wife & $85(21.5)$ & $50(12.7)$ & $0.87(0.49,1.53)$ & $1.5(0.55,3.96)$ \\
\hline Student & $17(4.3)$ & $25(6.3)$ & $0.35(0.16,0.74)$ & $0.6(0.20,2.03)$ \\
\hline \multicolumn{5}{|c|}{ Economic status (monthly income) } \\
\hline$\leq 765 \mathrm{ETB}(47.8 \mathrm{USD})$ & 134(32.1) & $75(18.0)$ & $1.2(0.82,1.80)$ & \\
\hline > 765 ETB(47.8USD) & 124(29.8) & $84(20.1)$ & $1.00^{*}$ & \\
\hline \multicolumn{5}{|l|}{ Residence } \\
\hline Urban & 185(44.4) & $111(26.6)$ & $1.1(0.71,1.69)$ & \\
\hline Rural & $73(17.5)$ & $48(11.5)$ & $1.00^{*}$ & \\
\hline \multicolumn{5}{|c|}{ Perceived presence of waiting area } \\
\hline Yes & $221(53.0)$ & $50(12.0)$ & 13.0(8.03,21.11) & $6.3(3.33,11.88)$ \\
\hline No & $37(8.9)$ & 109(26.1) & $1.00^{*}$ & $1.00^{*}$ \\
\hline \multicolumn{5}{|l|}{ Mode of visit } \\
\hline Referral & 104(24.9) & $59(14.2)$ & $1.1(0.76,1.72)$ & \\
\hline Not referral & 154(36.9) & $100(24.0)$ & $1.00^{*}$ & \\
\hline \multicolumn{5}{|c|}{ Waiting time before seeing a doctor or a nurse } \\
\hline$\leq 1$ hour & 247(59.2) & 135(32.4) & 4.0(1.89,8.40) & $2.9(1.14,7.58)$ \\
\hline$>1$ hours & $11(2.6)$ & 24(5.8) & $1.00^{*}$ & $1.00^{*}$ \\
\hline \multicolumn{5}{|c|}{ Privacy during examinations } \\
\hline yes & 179(42.9) & 40(9.6) & $6.7(4.32,10.52)$ & $2.1(1.13,3.83)$ \\
\hline No & $79(18.9)$ & 119(28.6) & $1.00^{*}$ & $1.00^{*}$ \\
\hline \multicolumn{5}{|c|}{ Amount paid to the service } \\
\hline$\leq 157 \mathrm{ETB}$ & 154(36.9) & $68(16.4)$ & $2.0(1.33,2.96)$ & $1.9(1.15,3.60)$ \\
\hline$>157 \mathrm{ETB}$ & 104(24.9) & $91(21.8)$ & $1.00^{*}$ & $1.00^{*}$ \\
\hline
\end{tabular}

*Reference group.

maternal condition after delivery, waiting time before seen by a health worker, perception about the waiting area for mothers and relatives, health professionals measure taken to assure privacy during maternal examinations, and service cost paid. This finding is consistent with other studies in Africa [11,12,18].

Mothers who wanted their pregnancy were more likely to be satisfied than mothers who did not. Similar finding 
Table 4 Obstetric experiences associated with mothers' satisfaction in referral hospitals of Amhara Region, Ethiopia, September -November, $2009(n=417)$

\begin{tabular}{|c|c|c|c|c|}
\hline Obstetric experiences & Satisfied & Unsatisfied & $\operatorname{COR}(95 \% \mathrm{Cl})$ & AOR $(95 \% \mathrm{Cl})$ \\
\hline \multicolumn{5}{|c|}{ Wanted status of pregnancy } \\
\hline Wanted & 212(50.9) & $96(23.0)$ & $\begin{array}{l}3.0(1.93,4.74)^{*} \\
*\end{array}$ & $\begin{array}{l}2.2(1.20,3.93)^{*} \\
*\end{array}$ \\
\hline Unwanted & $46(11.0)$ & $63(15.1)$ & $1.00^{*}$ & $1.00^{*}$ \\
\hline \multicolumn{5}{|l|}{ Mode of delivery } \\
\hline SVD & 142(34.0) & $82(19.7)$ & $\begin{array}{l}1.7(1.04,2.77)^{*} \\
*\end{array}$ & $1.2(0.50,2.69)$ \\
\hline Assisted delivery & $70(16.8)$ & $32(7.7)$ & $\begin{array}{l}2.1(1.19,3.84)^{*} \\
*\end{array}$ & $1.5(0.60,3.93)$ \\
\hline Caesarean section & $46(11.0)$ & $45(10.8)$ & $1.00^{*}$ & $1.00^{*}$ \\
\hline \multicolumn{5}{|l|}{ Maternal condition } \\
\hline Normal & $226(54.2)$ & 102(24.4) & $\begin{array}{l}3.9(2.41,6.46)^{*} \\
*\end{array}$ & $\begin{array}{l}2.1(1.12,3.93)^{*} \\
*\end{array}$ \\
\hline With complication & $32(7.7)$ & $57(13.7)$ & $1.00^{*}$ & $1.00^{*}$ \\
\hline \multicolumn{5}{|l|}{ Fetal outcome } \\
\hline Lived & 232(55.6) & 142(34.1) & $1.1(0.56,2.04)$ & \\
\hline Died & $26(6.2)$ & $17(4.1)$ & $1.00^{*}$ & \\
\hline \multicolumn{5}{|l|}{ ANC follow up } \\
\hline Yes & $227(54.4)$ & $124(29.8)$ & $\begin{array}{l}2.1(1.22,3.51)^{*} \\
*\end{array}$ & $1.3(0.58,3.03)$ \\
\hline No & $31(7.4)$ & $35(8.4)$ & $1.00^{*}$ & $1.00^{*}$ \\
\hline
\end{tabular}

*Reference group.

was reported in Kenya by Bazent and her colleagues [11]. The study also showed that mothers without complication were more likely to be satisfied than mothers with complication. Women who experience no complications may be happy that they survived and this may result satisfaction with care [11].
In studies conducted in Oromia and Afar Regions of Ethiopia, mothers were complaining payment for service, inadequate privacy and unfriendly attitude of care providers $[7,20]$. Similarly, in this study the researchers found privacy and cost incurred for service to be associated with mothers' dissatisfaction. Mothers who

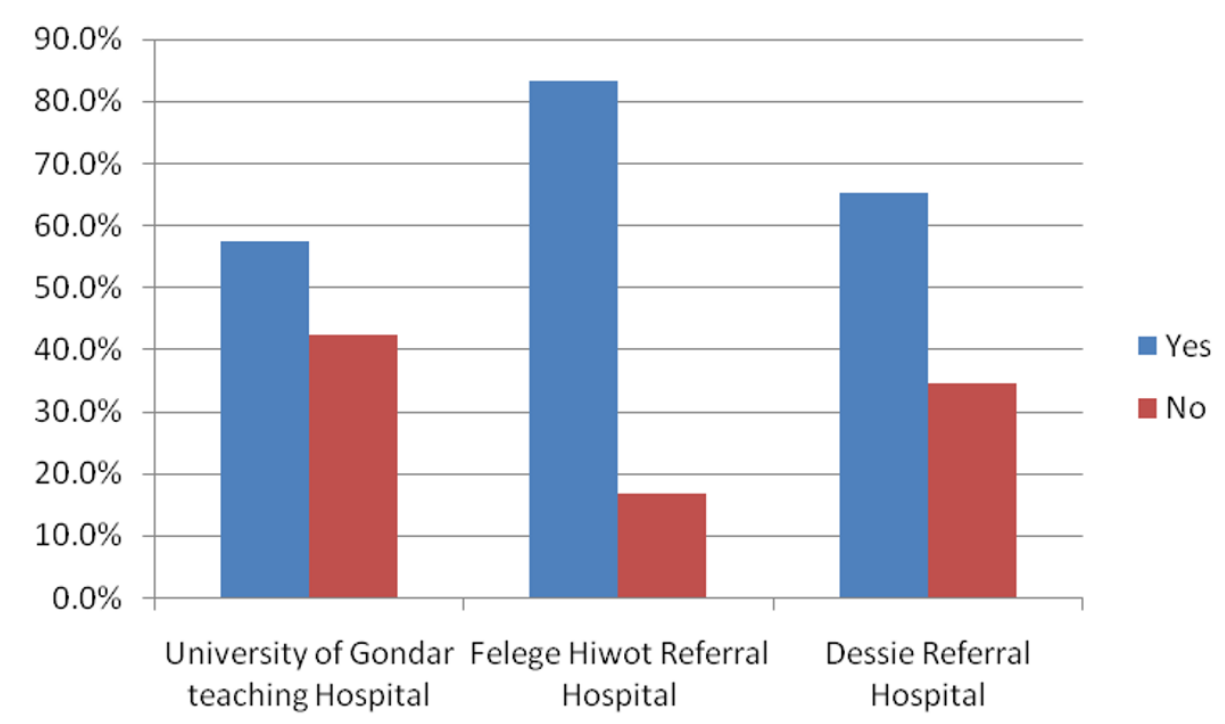

Figure $\mathbf{2}$ Will you recommend the hospital to family and friends? 
reported privacy during physical examination were more satisfied than those who perceived absence of privacy. This reflects there is privacy breach which should be improved. The mothers' level of satisfaction was also related to the amount of money paid for service as mothers who paid less than or equal to157 ETB were more satisfied than those who paid greater than 157 ETB. This might be due to the low socio economic status of the mothers or/and mothers may have paid unexpected costs such as cost for travel and charge for supplies.

Our finding showed that nearly two-thirds of all women were very likely to recommend the delivery care facility to friends and family. Though this suggests that the hospitals are providing an acceptable quality of care, there is room for substantial improvement at University of Gondar Teaching and Referral Hospital.

The findings of this study had limitations. First, data are restricted to delivery experience to referral hospital thereby limiting generalization to the overall health facility experience of childbirth by women. Second, potential response biases often present in patient satisfaction studies related to social desirability. We tried to minimize this bias by interviewing mothers in a separate room by trained nurses who are not affiliated with the facilities studied.

\section{Conclusions}

The overall satisfaction of hospital delivery services in this study is found to be suboptimal. The study strongly suggests that more could be done to assure that services provided are more patient centered.

This study also revealed several constraints in the provision of delivery care services which can be implied as areas of possible improvement, including poor maintenance of clients' privacy, longer waiting time, and unavailability of waiting areas.

\section{Acknowledgements}

We would like to extend our deepest gratitude to the University of Gondar for financing this research.

Our appreciation goes to the data collectors and supervisors who helped us in monitoring and supervising the data collection process. Our special thanks also go to heads of the maternity wards at University of Gondar Teaching and Referral Hospital, Felege Hiwot Referral Hospital and Dessie Referral Hospital, and delivering mothers who participated in the study.

\footnotetext{
Author details

'Department of Public Health, Bahir Dar University, P.O.Box 79, Bahir Dar, Ethiopia. ${ }^{2}$ Department of Epidemiology and Biostatistics, University of Gondar, P.O.Box 196, Gondar, Ethiopia.
}

\section{Authors' contributions}

AT wrote the proposal, participated in data collection, analyzed the data and drafted the paper. DTZ and YK approved the proposal with some revisions, participated in data analysis and revised subsequent drafts of the paper. All authors read and approved the final manuscript.

\section{Competing interests}

The authors declare that they have no competing interests.

Received: 30 March 2011 Accepted: 24 October 2011

Published: 24 October 2011

\section{References}

1. WHO, UNICEF, UNFPA, WORLDBANK: Maternal mortality in 2005:Estimates developed by WHO, UNICEF,UNFPA and the World Bank. Geneva: WHO; 2007.

2. Federal Democratic Republic of Ethiopia Central Statistical Agency OM: EDHS 2005. Addis Ababa,Ethiopia; 2006.

3. Mekonnen Y: Patterns of maternity care service utilization in Southern Ethiopia: Evidence from a community and family survey. Ethiopian journal of Health and Development 2003, 17(1):27-33.

4. FMOH: Health and Health Related Indicators. Addis Ababa: Policy, Plan and Finance General Directorate, Federal Ministry of Health Ethiopia; 2010.

5. FMOH: Ethiopian health sector development programme HSDP III 2005/ $06-2010 / 11$ (GC) (1998 - 2003 EFY) Mid-term review. Addis Ababa: Federal Ministry of health Ethiopia; 2008.

6. Nigussie M, Haile Mariam D, Mitike G: Assessment of safe delivery service utilization among women of childbearing age in north Gondar Zone, North West Ethiopia. Ethiopian journal of Health and Development 2004 18(3):145-152.

7. Fenta M: Assessment of factors affecting utilization of maternal health care services in Ayssaita and Dubti towns, Afar regional state, North east Ethiopia. MPH thesis Addis Ababa University; 2005.

8. Donabedian A: An Introduction to Quality Assurance in Health Care. Oxford University Press, USA; 2002.

9. Donabedian A: The quality of care. How can it be assessed? 1988. Archives of Pathology \& Laboratory Medicine 1997, 121(11):1145-1150.

10. West away MS RP, Vanzyl D, Seager JR: Interpersonal and organizational dimensions of patient satisfaction. International journal for quality in health care 2003, 15(4):337-344.

11. Bazant ES, Koenig MA: Women's satisfaction with delivery care in Nairobi's informal settlements. International Journal for Quality in Health Care 2009, 21(2):79-86.

12. Senarath U, Fernando DN, Rodrigo I: Factors determining client satisfaction with hospital-based perinatal care in Sri Lanka. Tropical Medicine \& International Health: TM \& IH 2006, 11(9):1442-1451.

13. Gamble J, Creedy DK, Teakle B: Women's expectations of maternity services: a community-based survey. Women and Birth: Journal of the Australian College of Midwives 2007, 20(3):115-120.

14. MacKeith N, Chinganya OJM, Ahmed Y, Murray SF: Zambian women's experiences of urban maternity care: results from a community survey in Lusaka. African Journal of Reproductive Health 2003, 7(1):92-102.

15. Goodman P, Mackey MC, Tavakoli AS: Factors related to childbirth satisfaction. Journal of Advanced Nursing 2004, 46(2):212-219.

16. Simkin P: Just another day in a woman's life? Part II: Nature and consistency of women's long-term memories of their first birth experiences. Birth (Berkeley, Calif) 1992, 19(2):64-81.

17. Simkin P: Just another day in a woman's life? Women's long-term perceptions of their first birth experience. Part I. Birth (Berkeley, Calif) 1991, 18(4):203-210.

18. Delvaux TG-KV, Bosso P, Collin S, Ronsmans C: Quality of normal delivery care in Côte d'Ivoire. Rev Afr Santé Reprod 2007, 11(1):22-32.

19. Janssen $P$, Klein M, Harris S, Soolsma J, Seymour L: Single room maternity care and client satisfaction. Birth 2000, 27(4):235-243.

20. ESOG: Utilization of Emergency Obstetric Care services in three woredas of west Shoa Zone, Oromia region, Ethiopia. Addis Ababa: Ethiopian Society of Obstetricians and Gynecologists; 2004

Pre-publication history

The pre-publication history for this paper can be accessed here: http://www.biomedcentral.com/1471-2393/11/78/prepub

doi:10.1186/1471-2393-11-78

Cite this article as: Tayelgn et al.: Mothers' satisfaction with referral hospital delivery service in Amhara Region, Ethiopia. BMC Pregnancy and Childbirth 2011 11:78 